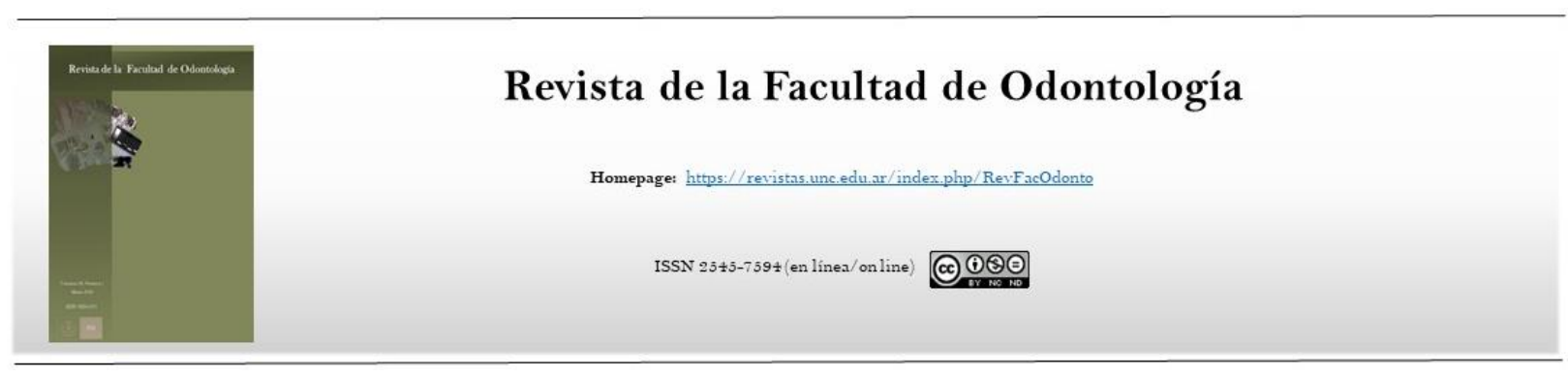

La ciencia en tiempos de pandemia

\title{
Science in times of pandemic
}

Brunotto $\mathrm{M}^{1}$

${ }^{1}$ Universidad Nacional de Córdoba. Facultad de Odontología. Departamento de Biología Bucal

Received 1 march 2020; Accepted 15 march 2020

Desde que se descubrió el SARS-COV 2 (del inglés Severe Acute Respiratory Syndrome Coronavirus 2) y se generó la pandemia por la enfermedad COVID-19 (del inglés Coronavirus disease 2019), producida por este virus, se han escrito alrededor de 44 y 84 artículos científicos, respectivamente, hasta el momento, sólo en la base PubMed. Estos artículos, especialmente los referidos a la enfermedad COVID-19, abarcan diferentes aspectos como diagnóstico, clínica y laboratorio, tratamiento, embarazo y parto $^{1-3}$. $\mathrm{La}$ información que se fue produciendo rápidamente ha ayudado a los gobiernos a tomar decisiones en el ámbito de la Salud Pública. Sin embargo, el trabajo silencioso y continuo de quienes todos los días investigan es el que seguramente aporte el conocimiento necesario para generar una vacuna o medicación para tratar a los enfermos graves ${ }^{1-3}$. En este marco tanto los desarrollos privados como del Estado son relevantes para avanzar de modo rápido $\mathrm{y}$ confiable, especialmente en casos como los que se suceden hoy en día, Por esto es importante aprovechar la información científica existente, de las ciencias naturales y sociales, para la toma de decisiones en Salud Pública ${ }^{4}$.

El proceso de toma de decisiones, por parte de políticos o directivos de organizaciones no gubernamentales, depende de factores como la existencia de redes de expertos confiables en sus áreas de investigación y que la información sea comprensible para éstos.

En épocas donde no existen emergencias sanitarias, quienes están a cargo de la toma de decisiones en salud cuentan con el tiempo

suficiente para analizar la información científica disponible y asesorarse por expertos. Sin embargo, en momentos de una emergencia sanitaria como en una epidemia o pandemia no hay un proceso claro para compilar y evaluar datos científicos publicados y puede que no existan redes confiables de expertos para asesorarse. Además, en general, los investigadores no están relacionados a responsables políticos. Los científicos creen que no son esenciales para la toma de decisiones a nivel de gobierno. Esta falta de interacción entre ciencia y política puede limitar la calidad y la objetividad de la información a la hora de tomar una decisión en Salud Pública.

En situaciones de emergencia, el tiempo y la dinámica de los hechos que se suceden, hacen que la confianza en la información científica y el asesoramiento por expertos sea importante. Los tomadores de decisiones con frecuencia no tienen tiempo para identificar y familiarizarse con la información científica existente; y en consecuencia estas brechas entre el conocimiento 
y su aplicación generan incertidumbre sobre la utilidad de los datos científicos.

Sin embargo, la cantidad de personas con enfermedades infecciosas a nivel mundial, así como las amenazas biológicas deliberadas, han permitido que se realicen significativas inversiones financieras en investigaciones de este tipo de enfermedades. No siempre los resultados obtenidos en estos estudios se traducen en prevención y detección de éstas ${ }^{4}$.

Es por ello que quienes trabajamos en ciencia debemos encontrar las vías adecuadas de comunicación para interactuar no solo con responsables políticos sino primeramente con la población a fin de prevenir situaciones de pandemias o epidemias.

El autor declara que no existen conflictos potenciales de interés con respecto a la autoría y / o publicación de este artículo.

The author declares no potential conflicts of interest with respect to the authorship and/or publication of this article

\section{Referencias}

1. Rodríguez-Morales AJ, Cardona-Ospina JA, GutiérrezOcampo E, et al. Clinical, laboratory and imaging features of COVID-19: A systematic review and metaanalysis Travel Med Infect Dis. 2020;101623. doi: 10.1016/j.tmaid.2020.101623

2. Adhikari SP, Meng S, Wu YJ, et al. Epidemiology, causes, clinical manifestation and diagnosis, prevention and control of coronavirus disease (COVID-19) during the early outbreak period: a scoping review. Infect Dis Poverty. 2020;9(1):29. Published 2020 Mar 17. doi:10.1186/s40249-020-00646-x

3. Wu D, Wu T, Liu Q, Yang Z. The SARS-CoV-2 outbreak: what we know [published online ahead of print, 2020 Mar 11]. Int J Infect Dis. 2020; S12019712(20)30123-5. doi: 10.1016/j.ijid.2020.03.004.

4. Berger KM, Wood JLN, Jenkins B, et al. Policy and Science for Global Health Security: Shaping the Course of International Health. Trop Med Infect Dis. 2019;4(2):60. Published 2019 Apr 10. doi:10.3390/tropicalmed4020060

Corresponding to /correspondencia a:

Dra. Mabel Brunotto

Departamento de Biología Bucal, Facultad de Odontología, Universidad Nacional de Córdoba. Haya de la Torre s/ n. Pabellón Argentina, Ciudad Universitaria.

E-mail/Correo electrónico:mabel.brunotto@unc.edu.ar 